\title{
A Study on the Influences of Exhibition Experience, Satisfaction, Brand Assets and Behavioral Intention
}

\author{
Seung-Wan Ju \\ Department of Financial Accounting/Real Estate Dong-Eui University, Busan, South \\ Korea \\ gauace@naver.com
}

\begin{abstract}
Currently, Korean companies operate corporate promotion halls, memorial halls and museums, centering on large corporations, making them a place for long-term communication beyond the short-term contact with consumers. In addition, companies have provided recently virtual exhibition experiences through the homepage or apps to the corporate publicity exhibition halls, which are operated by the company, and are being developed in parallel with the existing exhibition experiences.Therefore, this study conducted an empirical analysis to find out the effect of the exhibit experience of the corporate publicity exhibition hall on the consumer behavioral intention with the subject of the visitors who have experienced the exhibition experience of the domestic corporate publicity exhibition hall. Followings are the implications for the results.The academic significance of this study is in that it investigated the relationship between satisfaction, brand assets, and behavioral intention through the exhibition experience in the corporate publicity exhibition hall by conducting empirical analysis of the relationship systematically. In addition, it is expected to be used as a practical basic material that can be more practical in producing exhibition experiences when newly opening a corporate publicity exhibition hall or remodeling an existing corporate publicity exhibition hall.
\end{abstract}

Keywords: Corporate publicity exhibition hall, Exhibition experience, Experience satisfaction, Brand assets, Behavioral intention

\section{Introduction}

Today's corporate publicity exhibition halls not only have their own product promotion functions, but also play the new media of communication through communication activities between companies and consumers, and provide information of their own companies, convenience facilities, and complex cultural spaces. However, the recognition and research on the corporate publicity exhibition hall is insufficient, and the empirical research on the effect is very lacking.

This study seeks to examine the impact of exhibition experience on satisfaction, brand assets and consumer behavior in order to present the necessity and development direction of the corporate museum. Therefore, the company presented its future development direction by identifying the merits and demerits of the current exhibition experience in the corporate museum and promoting the improvement plan. Based on the research results obtained through

Article history:

Received (January 8, 2020), Review Result (February 14, 2020), Accepted (April 6, 2020) 
empirical analysis, the government should develop a space to enhance intimacy with companies and meet diverse needs of consumers through information exchange and communication between consumers and businesses. We also want to explore ways to develop into a space for local culture that contributes to the provision of cultural services and local culture through state-of-the-art exhibition and production techniques for consumers and potential customers.

\section{The theoretical background}

\subsection{Corporate publicity exhibition hall}

According to the definition specified in the Museum Act, the corporate museum is included in the categories of science museum, industrial technology museum and history museum, and is a special museum that specializes in detailed collections. Jeong-Suk Hyeong (2002) argued that the company museum generally refers to a specialized museum, and is an exhibition facility that specializes in storing information and materials in a specific field [1].

\subsection{Exhibition experience}

Experience refers to a series of processes [2] obtained through experience. Therefore, the exhibition experience means the experience that is felt through a series of process to meet the desire to see and motivation. Exhibit experiences induce active participation by stimulating interest and intellectual curiosity to visitors through a new exhibition production method. Visitor's participation aims to enhance the original meaning of the exhibition, which stimulates the viewer's emotion and inputs information due to the experience through five senses [3].

\subsection{Satisfaction}

Satisfaction is a complex concept, which refers to the degree of achieving motivation by basic human needs, as discussed in the behavioral science, and in the lexical sense, is originated from the Latin words 'SARIS' and 'FACERE' meaning filling, or fulfillment [4].

Visitor's satisfaction is the concept of the overall evaluation of the corporate publicity exhibition hall. Satisfaction degree is the consumption associated with the product and service characteristics or the product and service itself. It can be defined as judgment on the consumption level related with accomplishment that satisfaction is provided to consumers, and as the degree of subjective judgment and evaluation of visitors.

\subsection{Brand assets}

Entering into the 1980s, asset valuation of a company's brand began to emerge as an important issue. In most cases, brand asset can be guaranteed a profit higher than non-branded products or products in companies, individuals and organizations. It can be said the combination of debt and assets related to brand names or symbols that are consistent, strong and differentiated compared to other competitors [5]. The research on the components that form brand asset was conducted centering around he researches of Aaker (1991) and Keller (1993) [6][7], and this study also composed elements of brand asset based on the brand asset component model of these two scholars.

\subsection{Behavioral intention}


Behavioral intention has been interpreted in various ways according to each research field or object of social science, and has been actively researched as a key element in the marketing field targeting consumer behavior [8]. Behavioral intention is a subjective function in which beliefs and attitudes are acted upon, and intention is perceived as an intermediate variable between individual attitudes and behaviors, and means individual's subjective state [9]. Therefore, the behavioral intention in the exhibition experience can be defined as the individual's will and belief that the viewers will express a specific future behavior before forming an attitude toward an object.

\section{The design of the research}

\subsection{Survey subject and research mode}

In order to conduct this study, a survey was conducted on the visitors to a domestic publicity exhibition hall in a personal branch filling way. In order to compare and examine the effect of exhibition experience, which is an independent variable, on experience satisfaction, brand asset and behavioral intention based on literary researches and previous studies, the research model is set as shown in [Figure 1].

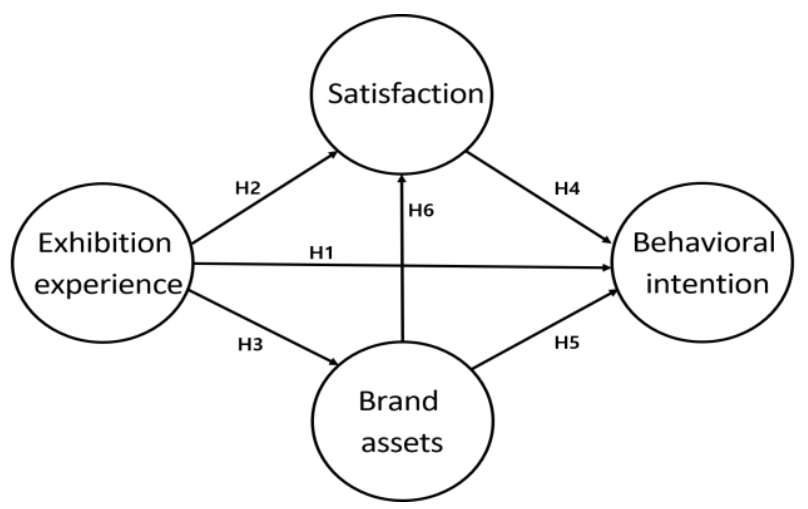

Figure 1. Research model

\subsection{Research hypothesis}

In this study, the following six hypotheses were established based on theoretical considerations on the premise that the exhibition experience in the corporate publicity exhibition hall will have a positive effect on behavioral intention.

Hypothesis 1. Exhibition experience will have a positive effect on behavioral intention.

Hypothesis 2. Exhibition experience will have a positive effect on satisfaction.

Hypothesis 3. Exhibition experience will have a positive effect on brand asset.

Hypothesis 4. Satisfaction will have a positive effect on behavioral intention.

Hypothesis 5. Brand asset will have a positive effect on behavioral intention.

Hypothesis 6. Brand asset will have a positive effect on satisfaction.

\section{The empirical analysis}

\subsection{Demographic characteristics of sample target}


According to the gender of the sample, 223 men (56.2 percent) and 174 women (43.8 percent), 40 people under 20 (10.1 percent), 80 people in their 30s (20.2 percent), 201 people in their 40s (50.6 percent), 60 people in their 50s (15.1 percent), and 16 visitors in their $60 \mathrm{~s}$ and older (4.0 percent) accounted for 69.7 percent of the total.

According to the survey, 116 people (29.2 percent) graduated from high school, 241 people (60.7 percent) graduated from college, and 40 people (10.1 percent) graduated from graduate school, the higher the willingness to visit the museum.

The number of visits was 277 (69.8 percent), 112 (19.2 percent), and 8 (2.0 percent) after the first visit, indicating that the rate of revisit after the first visit was significantly lower, while the rate of stay was 48 people (12.1 percent), 202 people (50.9 percent), and 147 people (37.0 percent) for one to two hours, from more than 30 minutes to less than two hours, according to the survey.

The purpose of the visit was 28 people $(7.1 \%)$ to purchase products, 95 people $(23.9 \%), 28$ people $(7.1 \%)$ to experience products, 151 people $(38.0 \%)$ to acquire information and learn information, and 95 people (23.9\%) to visit each other, and all types of visits were found to be individual visits.

\subsection{Confirmatory factor analysis}

The overall confirmatory factor analysis model of this study shows that $\mathrm{CMIN}=1280.435$ $(\mathrm{p}<0.001), \mathrm{df}=531, \mathrm{CMIN} / \mathrm{df}=2.411, \mathrm{GFI}=.858, \mathrm{AGFI}=.821, \mathrm{NFI}=.844, \mathrm{RMR}=.044$, RMSEA $=.060$, and CFI $=0.928$ as shown in [Table 1], confirming that the confirmatory factor analysis model considering the correlation between concepts can be seen as a suitable level.

Table 1. Conformance index of confirmatory factor analysis

\begin{tabular}{|c|c|c|c|c|c|c|c|c|c|c|c|}
\hline & CMIN & DF & RMR & GFI & AGFI & NFI & RFI & IFI & TLI & CFI & RMSEA \\
\hline Results & $1,280.435$ & 531 & .044 & .858 & .821 & .884 & .862 & .928 & .914 & .928 & .060 \\
\hline Criteria & $\mathrm{X}^{2} \mathrm{df} \leq 3$ & $\leq .05$ & $\geq .9$ & $\geq .9$ & $\geq .9$ & $\geq .9$ & $\geq .9$ & $\geq .9$ & $\geq .9$ & $\leq .05$ \\
\hline
\end{tabular}

\subsection{Hypothesis test}

\subsubsection{Fitness of research model}

In this study, the fitness of the model was evaluated by using CMIN, GFI, AGFI, NFI, TLI, RMR, and RMSEA. As a result of testing this model, the suitability index showed that Qvalue was 2.364, which is smaller than the recommended acceptance level of 3, GFI was 968 and TLI (Lisrel's NNFI) was .973, which was over 0.90, the suitability index of GFI and TLI, showing satisfaction, and the RMSEA value was also .059, which is included in the suitability index of 0.05 to 0.08 , indicating the level of satisfaction. Therefore, the hypothesis test was conducted by judging that the relational model presented in this study is consistent with the analytical data obtained in reality on the satisfactory level.

Table 2. Fitness of research model

\begin{tabular}{|c|c|c|}
\hline Suitability & Recommended acceptance level & Analysis Results \\
\hline $\mathrm{CMIN}\left(\mathrm{X}^{2}\right)$ & - & 68.566 \\
\hline
\end{tabular}




\begin{tabular}{|c|c|c|}
\hline DF & - & 29 \\
\hline Q(CMIN/DF $)$ & $\leq 3$ & 2.364 \\
\hline P & $\geq .05$ & .000 \\
\hline GFI & $\geq .9$ & .968 \\
\hline AGFI & $\geq .9$ & .931 \\
\hline NFI & $\geq .9$ & .976 \\
\hline TLI & $\geq .9$ & .973 \\
\hline RMR & $\leq .05$ & .033 \\
\hline RMSEA & $\leq .05$ & .059 \\
\hline
\end{tabular}

\subsubsection{Results of verification of structural equation model}

The structural equation model was set up for the research model set in this study, and the analysis results of the structural equation model in this study are shown in [Figure 2].

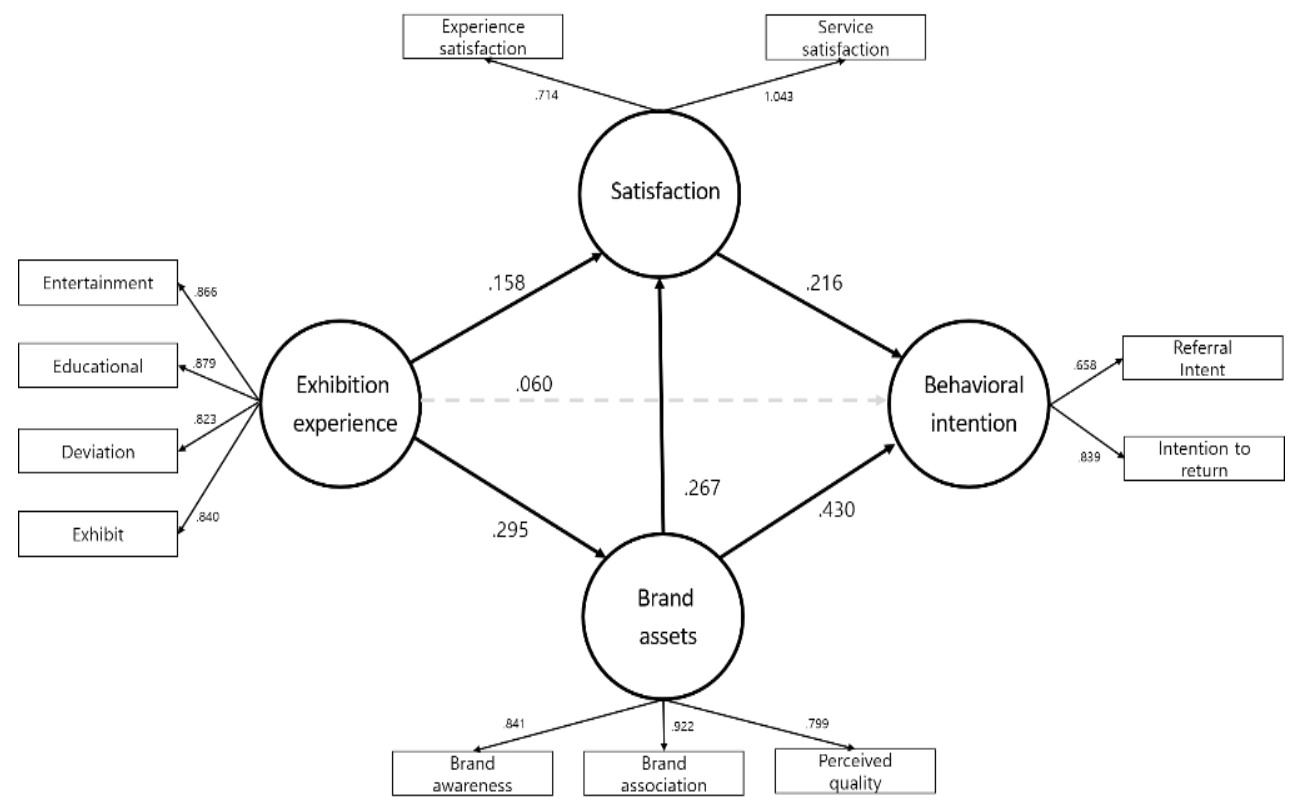

Figure 2. Path coefficient result value of structural equation model

Table 3. Hypothesis test results

\begin{tabular}{|c|c|c|c|c|c|c|c|c|c|}
\hline \multicolumn{4}{|c|}{ Route } & $\begin{array}{c}\text { Non- } \\
\text { standardization } \\
\text { Coefficient }\end{array}$ & $\begin{array}{c}\text { Standardization } \\
\text { Coefficient }\end{array}$ & S.E & C.R. & P & $\begin{array}{c}\text { Adoption } \\
\text { or not }\end{array}$ \\
\hline H1 & $\begin{array}{c}\text { Exhibition } \\
\text { experience }\end{array}$ & $\rightarrow$ & $\begin{array}{c}\text { Behavioral } \\
\text { Intention }\end{array}$ & .051 & .060 & .045 & 1.121 & .262 & Dismiss \\
\hline H2 & $\begin{array}{c}\text { Exhibition } \\
\text { experience }\end{array}$ & $\rightarrow$ & Satisfaction & .177 & .158 & .055 & 3.211 & $.001^{* * *}$ & Adoption \\
\hline H3 & $\begin{array}{c}\text { Exhibition } \\
\text { experience }\end{array}$ & $\rightarrow$ & $\begin{array}{c}\text { Brand } \\
\text { Asset }\end{array}$ & .289 & .295 & .053 & 5.473 & $.000^{* * * *}$ & Adoption \\
\hline H4 & Satisfaction & $\rightarrow$ & $\begin{array}{c}\text { Behavioral } \\
\text { Intention }\end{array}$ & .161 & .216 & .041 & 3.962 & $.000^{* * *}$ & Adoption \\
\hline H5 & Brand & $\rightarrow$ & Behavioral & .369 & .430 & .049 & 7.455 & $.000^{* * *}$ & Adoption \\
\hline
\end{tabular}




\begin{tabular}{|c|c|c|c|c|c|c|c|c|c|}
\hline & Asset & & Intention & & & & & & \\
\hline H6 & $\begin{array}{c}\text { Brand } \\
\text { Asset }\end{array}$ & $\rightarrow$ & Satisfaction & .307 & .267 & .058 & 5.306 & $.000 * * *$ & Adoption \\
\hline
\end{tabular}

Followings are the results of analysis of the structural equation model. First, the variables influencing the exhibition experience are entertainment experience, education experience, deviation experience, and aesthetic experience. The most influential variables were educational experience, followed by entertainment experience, aesthetic experience, and deviation experience. Second, the variables influencing satisfaction were exhibited exhibition satisfaction and exhibition service satisfaction. Among the two variables, exhibition service satisfaction was the more influencing variable. Third, the variables influencing brand asset are brand recognition, brand association, and perceived quality. The most influencing variable was brand association, followed by brand awareness and perceived quality. Lastly, the variables influencing behavioral intention, which are dependent variables, were recommendation intention and revisit intention, and the more influential variable was revisit intention.

\section{The conclusion}

In order to understand the effect of the exhibition experience on satisfaction and behavioral intention at the corporate publicity exhibition hall, this study analyzed empirically the effect of four experience elements (entertainment experience, education experience, deviation experience, and aesthetic experience) proposed by Pine \& Gilmore on satisfaction and behavioral intention. The implications based on the research results are as follows.

First, as a result, the corporate publicity exhibition hall did not have much effect on the behavioral intention of customers simply by exhibiting and viewing. This might indicate that companies that operate or prepare to open corporate publicity exhibition hall should avoid such simple experiences or simple viewing facilities. Second, the corporate publicity exhibition hall cannot induce customers' behavior simply by exhibiting experiences. If the corporate publicity exhibition hall is operated in combination with the brand assets of the company presented in this research or tangible and intangible assets of other companies, more efficient results will be anticipated. Third, as derived from the results of the study, corporate product brands are exposed to consumers daringly, and they work very sensitive to consumers, affecting their behavioral intention. The positive image of a product brand will lead to satisfaction and behavioral intention, which in turn will affect the company's sales growth. Therefore companies should be very careful in product brand management.

The academic significance of this study is in that it investigates the relationship between satisfaction, brand assets, and behavioral intention through the exhibition experience in the corporate publicity exhibition hall by analyzing their structure empirically. In addition, it is expected that it can be used as a practical basic material that can be more practical in producing exhibition experiences when newly opening a corporate publicity exhibition hall or remodeling the existing one.

\section{References}

[1] Jung-Suk Hyeong, "Structure of exhibition scenario and space arrangement programming in the enterprise museum,” M.S. thesis, Seong-Gyun-Gwna University, Seoul, Korea, pp.5, (2002)

[2] Gum-Ho Lee, "A study on the effect of traditional cultural experience on touring satisfaction and behavioral intention,” Ph.D. dissertation, Se-Han University, Dang-Jin, Korea, pp.23, (2017) 
[3] Won-Gil Kim, "A study on the characteristics of medium and production for improved sensibility interface of exhibit space," M.S thesis, Hong-Ik University, Seoul, Korea, pp.45, (2003)

[4] Min-Chae. Jeung, "The impact that educational attributes, brand value, and properties of choice influence to tourism satisfaction and behavioral intention in historical and cultural sites," Ph.D. dissertation, Kyung-Hee University, Seoul, Korea, pp.28, (2009)

[5] Min-Seok Kwak and Kwang-Min Cho, "The relationships among brand equity, brand value, customer satisfaction, brand attitude, and revisit intention in golf," Korean journal of physical education, vol.50, no.1, pp.147-160, (2011)

[6] Aaker, "The value of brand quality," The Journal of Business Strategy, vol.38, no.3, pp.102-120, (1991)

[7] Keller K. L and Conceptualizing, "Measuring and managing customer-based brand equity," Journal of Marketing, vol.57, no1, pp.1-22, (1993)

[8] Eun-Hye Cho, "The impacts of the suitability and attractiveness of the dining space facade on customer awareness and behavior intention," Ph.D. dissertation, Kyong-Gi University, Seoul, Korea, pp.36, (2015)

[9] Yung-Kon Kim, "The relationship among motive of visitation, image of tourism, satisfaction, behavioral intentions of visitor taekeondo festival," Ph.D. dissertation, Kyung-Hee University, Seoul, Korea, pp.34, (2009) 
The Significance of Preplanning and Faculty Engagement in Curriculum Change

This page is empty by intention. 